\title{
Influence of Magnetic Water on Strength Properties of Concrete
}

\author{
B. Siva Konda Reddy ${ }^{*}$, Vaishali G. Ghorpade ${ }^{2}$ and H. Sudarsana Rao ${ }^{2}$ \\ 'Dept. of Civil Engg., JNTUH College of Engineering, Hyderabad, A.P, India; bskreddy_246@Jntuh.ac.in \\ 2Dept. of Civil Engg., JNTUA College of Engineering, Anantapur, A.P, India; ghorpade_vaishali@yahoo.co.in; \\ hanchate123@yahoo.co.in
}

\begin{abstract}
It is expected that in the near future, the civil engineering community will have to produce structures in harmony with the concept of sustainable development through the use of high-performance materials with low environmental impact that are produced at a reasonable cost. Magnetic water concrete, synthesized from the normal materials used for manufacturing of concrete, provides one route towards this objective. This paper presents the effect of addition of magnetic water on workability, strength and mechanical properties of concrete tested show-encouraging results, and one can easily replace normal water with magnetic water by which quantity of cement used in any concrete mix reduces and can be made as new Eco-friendly construction material for future decades.
\end{abstract}

Keywords: Magnetic Water (MW), Structure of MW, North \& South Poles, Workability, Strength, Stiffness.

\section{Introduction}

Magnetized water doesn't mean water has acquired magnetic strength but that it has been subjected to a magnetic field which is found to change certain properties of water. These anomalous properties of water are unique and may result in many variations of macroscopic properties. Water is not homogeneous at the nanoscale and exists as clusters depending on the temperature, pressure and existing forces. Thus the density of the water may also change depending on the forces that dominate the conditions. The two forces that dominate are hydrogen bond and vanderwaal's forces.

The magnetic field can break down these water clusters and reduce the bond angle and hence increase solubility ${ }^{1}$. It is believed that after applying a strong magnetic field, water will show diamagnetism. Diamagnetism refers to substances that are magnetized in a way opposite to the direction of magnetic field, having pair-up electrons which cancel each other's magnetic moment because the two electrons in a pair-up rotate opposite to each other. As a result, water molecules are 'directed' to have certain orientation $^{2}$ as shown in Figure1.

Since water molecules are fixed in orientation, they are restricted to form water clusters due to chances of reducing matched orientation of water molecules in a cluster. Hydrogen bonds' association percentage will decrease. In other words, larger water clusters are cut and broken down by external magnetic field to form smaller water clusters or double water molecules $\left[\left(\mathrm{H}_{2} \mathrm{O}\right)\right.$ 2] or even single water molecule $\left(\mathrm{H}_{2} \mathrm{O}\right)$. Yan et al. ${ }^{1}$ also states that by light spectrum, the bond angle decreases from $104.5^{\circ}$ to $103^{\circ}$ because magnetic field deflects the bond pairs and squeezes the bond pairs to be closer together (Figure 2). Decreased bond angle also reduces repulsion between electrons in bond pairs of $\mathrm{H}_{2} \mathrm{O}$ and electrons in solute molecules/ions because the bond pairs have a narrower coverage and water molecules contract in terms of electric field. As a result, energy for acquiring stability is lower and more solute can be packed in the same volume

${ }^{*}$ Author for correspondence: 


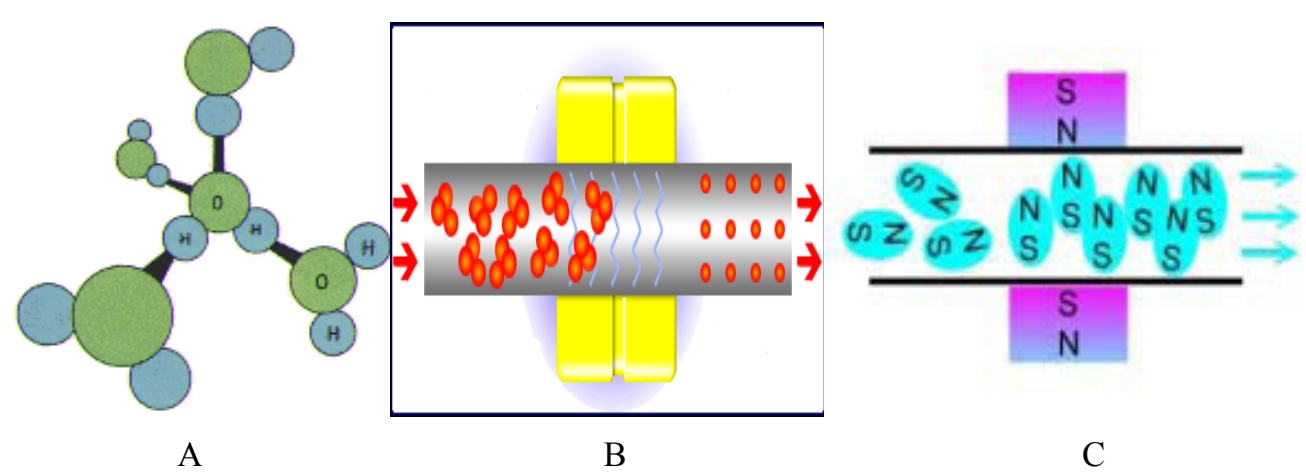

Figure 1. Mechanism of magnetic water: A. water cluster; B. breakage of cluster; C. orientation.

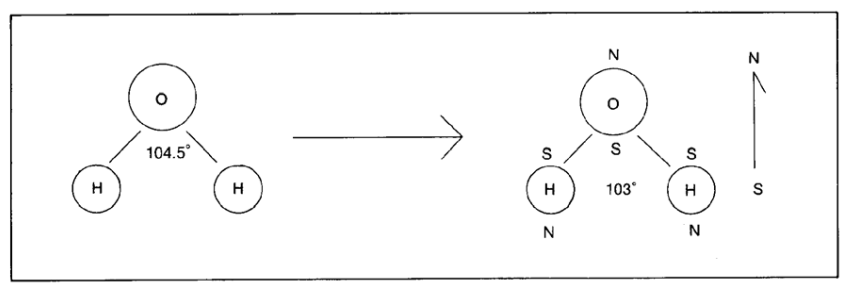

Figure 2. The decrease in bond angle in water molecule exposed to magnetic field.
Table 1. Physical properties of aggregates used in the mix

\begin{tabular}{llcc}
\hline S.No. & Properties & $\begin{array}{l}\text { Fine } \\
\text { aggregate }\end{array}$ & $\begin{array}{l}\text { Coarse } \\
\text { aggregate }\end{array}$ \\
\hline 1 & Fineness modulus & 2.88 & 7.23 \\
2 & Specific gravity & 2.60 & 2.60 \\
3 & Bulk density in lose & $1550 \mathrm{~kg} / \mathrm{m}^{3}$ & $1360 \mathrm{~kg} / \mathrm{m}^{3}$ \\
& state & & \\
\hline
\end{tabular}

Table 2. Physical properties of cement used in the mix

\begin{tabular}{lcccccc}
\hline Property & $\begin{array}{c}\text { Specific } \\
\text { gravity }\end{array}$ & $\begin{array}{c}\text { Fineness } \\
\text { (by sieve) }\end{array}$ & $\begin{array}{c}\text { Initial } \\
\text { setting time }\end{array}$ & $\begin{array}{c}\text { Final } \\
\text { setting time }\end{array}$ & $\begin{array}{c}\text { Compressive } \\
\text { strength (28 Days) }\end{array}$ & Soundness \\
\hline Result & 3.02 & $3 \%$ & $52 \mathrm{~min}$ & $560 \mathrm{~min}$ & $54.7 \mathrm{~N} / \mathrm{mm}^{2}$ & $2 \mathrm{~mm}$ \\
\hline
\end{tabular}

of water because electric field of each $\mathrm{H}_{2} \mathrm{O}$ molecule contracts, thus increasing solubility of water ${ }^{3}$.

\section{Scope of the Present Study}

Concrete based on Portland Cement (PC) is extensively used construction material, given that it is more economical (compared to metals and other materials). One of the negative aspects of $\mathrm{PC}$ is that its fabrication generates $\mathrm{CO}_{2}$ through calcination of raw materials and fuel consumption. It is calculated that 1 ton of PC generates 1 ton of $\mathrm{CO}_{2}^{4}$. The present paper investigates the method of improving strength of given grade of concrete by reducing the usage of cement in a mix without effecting the other properties of concrete by replacing normal water with magnetic water for mixing of ingredients in concrete.

\section{Constituents of Magnetic Water Concrete (MWC)}

In the present investigation work, magnetic water was prepared by retaining water in a glass beaker over a round magnet of 985 Gauss magnetic field that was obtained from scientific store. The Magnetic water was produced by placing the beaker filled with water over the magnets for a period of 24 hours $^{5}$ as shown in Figure 8. During this time, the magnetic field penetrates through the glass into the water and this magnetized water is used for making concrete. Natural sand obtained from the local market is used as fine aggregate. The crushed coarse aggregates of $12 \mathrm{~mm}$ and $20 \mathrm{~mm}$ maximum size, obtained from the local crushing plants were used in the present investigation. The physical properties of fine and coarse aggregate such as specific gravity, gradation, and fineness modulus were tested in concurrence of IS: 2386 as shown in Table 1. 53-Grade ordinary Portland cement was used. The physical properties are shown in Table 2.

\section{Mix Proportions of MWC}

The investigation work on M20 grade of concrete mix trials was carried out on procured material. The Indian standard mix design procedure was adopted (i.e., IS: 10262-2009) to arrive at the mix proportions for M20 
grade of concrete. The detailed mix design procedure of M20 grades of concrete is given in Table 3.

\section{Manufacturing and Testing of MWC}

The Trial mix was fixed as shown in Table 3 using three different magnetic water: 1 . Water exposed to North Pole $(\mathrm{N})$ 2. Water exposed to South Pole and 3. Mixed pole water $(\mathrm{N}+\mathrm{S}$, half North Pole and half South Pole waters). Two types of waters (Normal Tap Water (TW) and Distilled water (DW)) were used. The magnetic water placed on magnet for 24 hour duration, considered to be optimum duration ${ }^{5}$ was added to the cement, and aggregates were prepared in saturated surface dry condition. The wet mix was usually in cohesive condition. The workability of the fresh concrete was measured by means of the conventional slump test. The prepared concrete mixture was casted in cubes, cylinders and beams. After removing the concrete cubes from the moulds, the specimens were placed in water tub and were left for curing, until they were loaded

Table 3. Trial mix proportions for $1 \mathrm{~m}^{3}$ of concrete

\begin{tabular}{lcc}
\hline S.No. & Material & Quantity in Kg \\
\hline 1 & Cement & 310 \\
2 & Sand & 719 \\
3 & 20mm Aggregates & 700 \\
4 & $12 \mathrm{~mm}$ Aggregates & 466 \\
5 & Water & 170.5 \\
\hline
\end{tabular}

Table 4. Slump test results for concrete with and without magnetic water

\begin{tabular}{llcccc}
\hline S.No. & Description & $\begin{array}{l}\text { Normal } \\
\text { water }\end{array}$ & & \multicolumn{3}{c}{ Magnetic water } \\
\cline { 3 - 6 } & & North & South & $\begin{array}{c}\text { North } \\
\text { \& South }\end{array}$ \\
\hline 1 & Tap Water & 50 & 50 & 50 & 55 \\
2 & $\begin{array}{l}\text { Distilled } \\
\text { water }\end{array}$ & 50 & 50 & 50 & 55 \\
\hline
\end{tabular}

Table 5. 7th day compressive strength of concrete with and without magnetic water in $\mathrm{N} / \mathrm{mm}^{2}$

\begin{tabular}{lllllc}
\hline S.No. & Description & Normal & \multicolumn{3}{c}{ Magnetic water } \\
\cline { 4 - 6 } & & water & North & South & $\begin{array}{c}\text { North } \\
\text { \& South }\end{array}$ \\
\hline 1 & Tap Water & 18.86 & 22.62 & 20.52 & 30.01 \\
2 & Distilled & 21.52 & 23.92 & 23.24 & 34.37 \\
& water & & & & \\
\hline
\end{tabular}

in testing machine for different tests at the specified age in accordance with the relevant Indian standards.

\section{Results and Discussions}

1. The workability results of slump for three different (kinds of) water: $\mathrm{N}, \mathrm{S}, \mathrm{N}+\mathrm{S}$ are presented in Table 4 and the results show that in case of the concrete made with mixed pole $(\mathrm{N}+\mathrm{S})$ magnetic water, the slump was slightly higher. Both mixes had good flow ability and there was no sign of bleeding as well as segregation. The concrete made with MWC was very greenish compared with Normal Water Concrete (NWC).

2. The compressive strength for 7 th day and 28 th day for the three kinds of water i.e., $\mathrm{N}, \mathrm{S}, \mathrm{N}+\mathrm{S}$ both using normal and distilled water are presented in Tables $5 \& 6$ respectively. It is shown in Figures $3 \& 4$ that the compressive strength of concrete increases with the usage of magnetized water, and this increase in the strength is due to cluster concept of water and also memory of water concept. The magnetized water is observed to have better bioavailability and is due to the reason that the clusters formed by the water in magnetized state are of smaller size. Usually, a water cluster consists of many water molecules of size 11-50 depending on the dominating force in the water molecule. But when water is exposed to magnetized field, it is observed

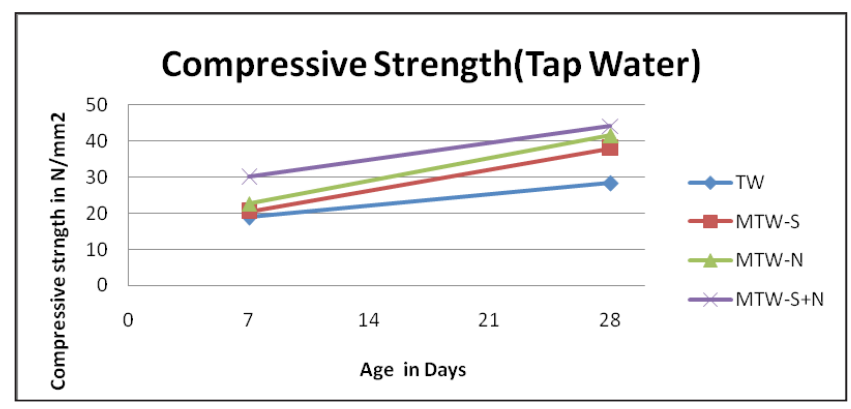

Figure 3. Compressive strength of concrete caste with and without magnetized tap water.

Table 6. 28th day compressive strength of concrete with and without magnetic water in $\mathrm{N} / \mathrm{mm}^{2}$

\begin{tabular}{lllllc}
\hline S.No. & Description & \multirow{2}{*}{$\begin{array}{l}\text { Normal } \\
\text { water }\end{array}$} & & \multicolumn{3}{c}{ Magnetic water } \\
\cline { 4 - 6 } & & & North & South & $\begin{array}{c}\text { North } \\
\text { \& South }\end{array}$ \\
\hline 1 & Tap Water & 28.29 & 41.5 & 38.01 & 44.06 \\
2 & Distilled & 30.64 & 42.92 & 40.91 & 45.02 \\
& water & & & & \\
\hline
\end{tabular}


that the number of water molecules decreases to a smaller amount and is, usually, of about the size 5-6. Thus, water when exposed to magnetic field has better dispersion (or in simpler terms increased specific area). As the more water is available for hydration, the more number of cement particles are hydrated, and this result in better quality and density of hydration products of cement. This increase in hydration may lead to increase in the compressive strength of the concrete. This effects increase in efficiency of cement used in concrete.

3. Split tensile strength \& Flexure strength of concrete with and without magnetic water are tabulated in Table $7 \& 8$. The results in Figures 5 \& 6 indicate that the split tensile strength and flexural strength of con-

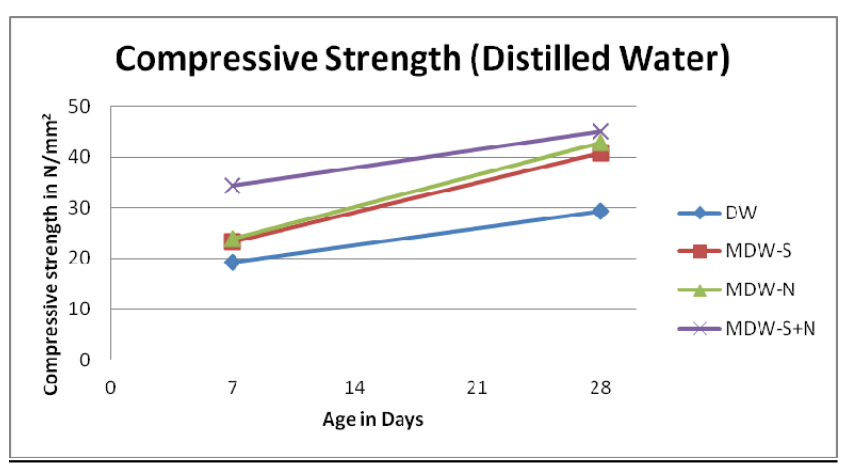

Figure 4. Compressive strength of concrete caste with and without magnetized distilled water.

Table 7. 28 days split tensile test results in $\mathrm{N} / \mathrm{mm}^{2}$

\begin{tabular}{lccc}
\hline Description & TW & MTW-(N+S) & MDW- $(\mathrm{N}+\mathrm{S})$ \\
\hline $\begin{array}{l}\text { Split Tensile } \\
\text { Strength }\end{array}$ & 2.54 & 2.86 & 3 \\
\hline
\end{tabular}

Table 8. Flexural strength test results in $\mathrm{N} / \mathrm{mm}^{2}$

\begin{tabular}{lcccc}
\hline S.No. & Days & TW & MTW-S+N & MDW-S+N \\
\hline 1 & 7 & 3.98 & 4.56 & 5.18 \\
2 & 28 & 5.2 & 6.32 & 6.5 \\
\hline
\end{tabular}

Table 9. Water absorption and density values for tap water and N\&S pole distilled water

\begin{tabular}{lccc}
\hline S.No. & Description & $\begin{array}{c}\text { \% of Water } \\
\text { Absorption }\end{array}$ & $\begin{array}{c}\text { Density } \\
\text { in } \mathbf{~ k g} / \mathrm{m}^{3}\end{array}$ \\
\hline 1 & Tap Water & 5.21 & 2490 \\
2 & $\begin{array}{c}\text { North and South pole } \\
\text { Magnetic distilled water }\end{array}$ & 3.51 & 2620 \\
\hline
\end{tabular}

crete increased with magnetization of tap water, and these values further improved with distilled magnetic water, and the reason for this improvement is discussed above.

4. Water absorption and density tests were conducted for all concrete mixes with and without magnetic water and are tabulated in Table 9. The results show that the concrete made with magnetic water is exhibiting more density and less water absorption. This is due to more hydration of cement due to magnetic effect, which reduced the pores in the concrete.

5. The load deformation plot is drawn for studying the effect of magnetic water on the behavior of concrete cylindrical specimens. As shown in Table 10 \& Figure 7 , the concrete cylindrical specimens with

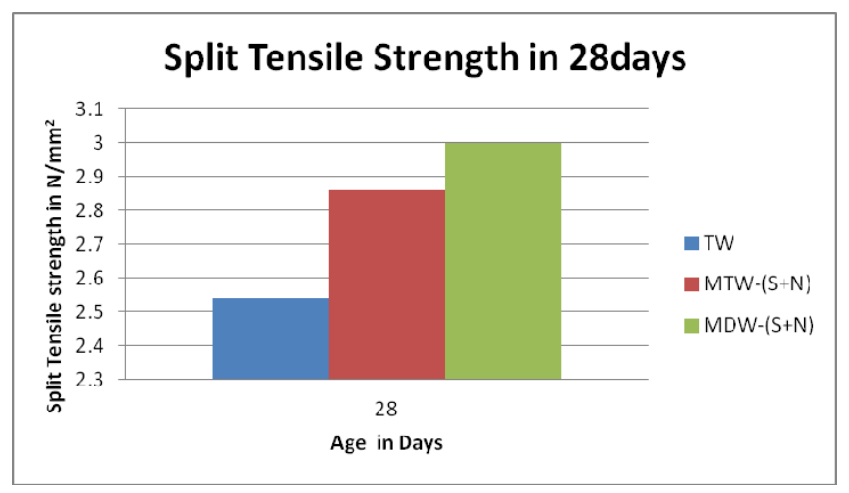

Figure 5. Comparison of split tensile strength for 28 days.

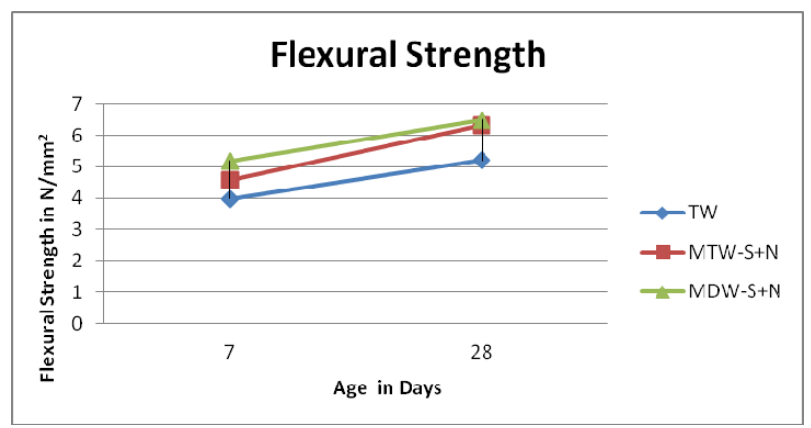

Figure 6. Comparison of flexural strength for concrete with and without magnetic water.

Table 10. Load-deformation test results for concrete with and without magnetic water

\begin{tabular}{lcc}
\hline Description & TW & MDW-(S+N) \\
\hline Load in KN & 264 & 312 \\
Deformation in mm & 8.29 & 6.18 \\
\hline
\end{tabular}




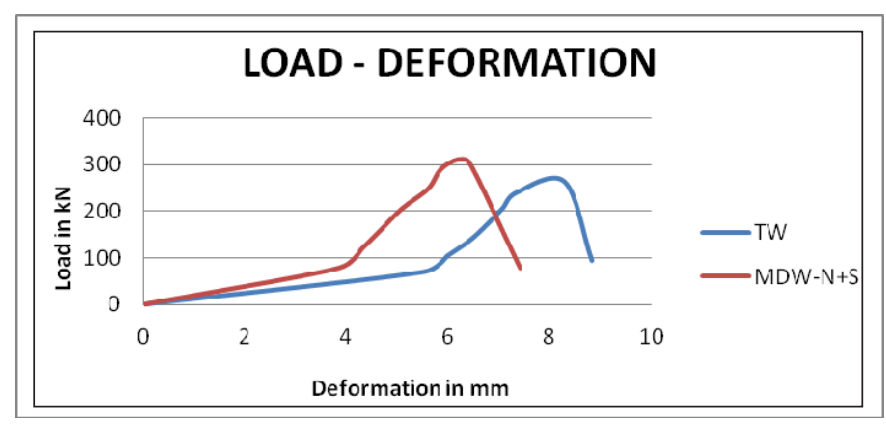

Figure 7. Load-deformation plot for concrete with and without MW.

magnetic water are carrying higher loads with less deformation compared to non magnetic concrete specimens at failure condition. Further, the stiffness of magnetized cylindrical specimens is increased by $59 \%$ as compared to concrete cylinders casted with non magnetized normal tap water.

\section{Conclusions}

This investigation shows the influence of magnetic water on workability (consistency) and strength properties of concrete. For this purpose, the magnetic water of 985 gauss strength is used. The conclusions obtained from this work are as follows:

- The workability of magnetic water concrete is slightly more than that of NWC.

- The density of magnetic water concrete is high and water absorption is less as compared to NWC.

- During magnetization of water the mixed pole water gave more compressive strength than North Pole and South Pole water.
- Magnetized Distilled water concrete showed more compressive strength than the Magnetized tap water concrete.

- The Compressive strength of Magnetized water concrete is more than that of NWC by $55 \%$.

- The Tensile strength of concrete is improved by $18 \%$ when Magnetic water is used instead of Normal water for preparing concrete.

- The Flexural strength of Magnetized water concrete is more than that of NWC by $25 \%$.

Magnetized water concrete cylindrical specimens are found to be $59 \%$ more stiffer than Normal water concrete cylindrical specimens.

\section{References}

1. Yan MC, Ting WO, Yeung TH et al. Chemistry of magnetic water. International Chemistry Olympiad.IChO'2009, UK; 2009.

2. Joe YY. Explore the relationship between Kazakhstan ear voltage and water magnetization variables and its effect on the compressive strength of cement mortar [Thesis Report]. China: National Central University, DCE; 2004.

3. De Silva KS. Studies on magnetic filtration techniques to purify potable water and waste water [Thesis Report]. New Zealand: Massey University, IIST; 2007.

4. Malhotra VM. Introduction: sustainable development and concrete technology. ACI Concr Int. 2002; 24(7):22-23.

5. Reddy BSK, Ghorpade VG, Rao HS. Effect of magnetic field exposure time on workability and compressive strength of Magnetic water concrete. Int J Adv Eng Tech. 2013; 4(3):120-122. 